\title{
Results of operational sea-wave monitoring with radar gauges
}

Sebastian Rütten, Stephan Mai, Jens Wilhelmi, Theodor Zenz, Hartmut Hein, Ulrich Barjenbruch (all: German Federal Institute of Hydrology $(B f G)$, Am Mainzer Tor 1, 56068 Koblenz)

Topic A: Innovations in acquisition techniques

\section{INTRODUCTION}

New developments off the German coasts, like offshore wind farms, require operational monitoring of waves nearby such offshore structures. Accordingly, several authors (for example [Mai 2008]) emphasized the need for reliable, continuous wave measurements. Therefore, the German Federal Institute of Hydrology - BfG (in cooperation with the German Federal Waterways Administration WSV developed a low-cost, non-contact monitoring system based on a single radar sensor. Such a system, for example, has been in operation since 2006 at the gauge "Lighthouse Alte Weser" in the estuary of the rivers Jade and Weser (see Figure 1).

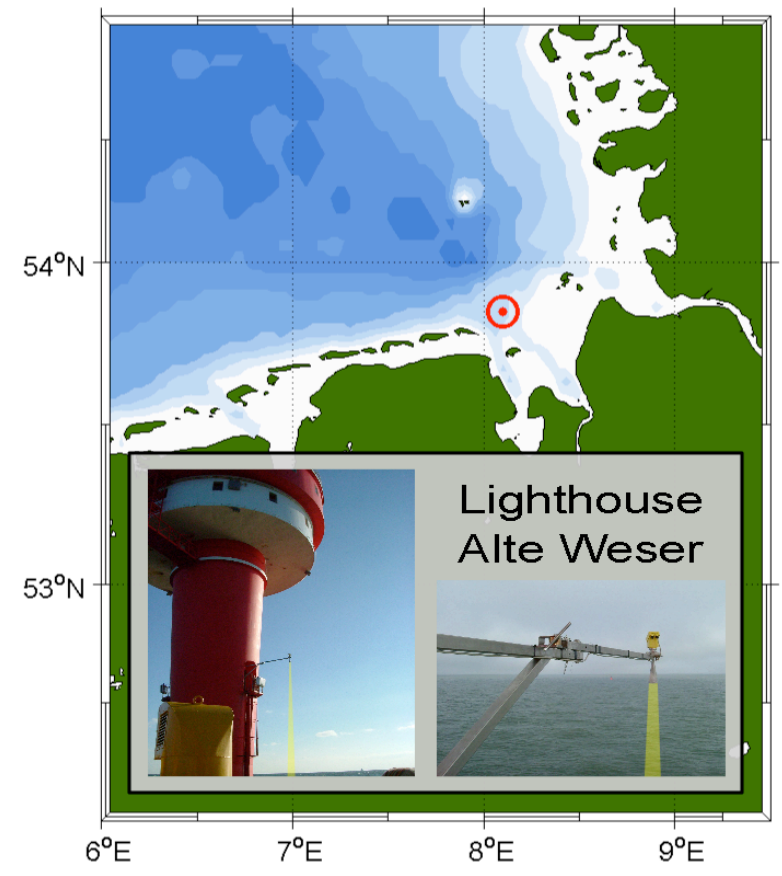

Figure 1: The operational wave monitoring system at the gauge "Lighthouse Alte Weser".

The purpose of this study is to analyse possible future changes in wave heights at the "Lighthouse Alte Weser". Therefore, a transfer function of wind speed to wave height was determined, also taking account of the wind direction. This function is used to derive predictions of changing wave heights due to expected future changes in wind statistics, as calculated by a global climate model. First of all, data acquisition and -processing are described in brief.

\section{DATA AND METHODS}

The data basis of this study consists of wave and wind measurements recorded in the period from May 2006 until August 2011. Furthermore, wind data that were generated by the climate model " ECHAM5" are assessed for the years 1970-2090. 


\section{WAVE MEASUREMENTS}

Many of the sensors that are commonly used to monitor the water-surface elevation (for example waverider buoys or pressure gauges) have to be installed directly in the water. This requires a lot of maintenance as those systems are permanently exposed to harsh environmental influences of the sea, such as wave attack or corrosion. For long-term measuring campaigns, sensors that are not directly in contact with the water are much more easily to operate and maintain. The described monitoring system, developed by the German Federal Institute of Hydrology $(B f G)$ in cooperation with the Federal Waterways and Shipping Administration (WSV) and the German Federal Maritime and Hydrographic Agency (BSH) meets this criterion.

The measuring setup consists of a commercial radar liquid-level sensor, which is fixed to the end of a joist that is attached to a coastal or offshore structure (as illustrated for the "Lighthouse Alte Weser" in Figure 1). The radar sensor emits electro-magnetic pulses at a frequency of $26 \mathrm{GHz}$ twice a second and, in turn, detects these pulses when they are backscattered at the water surface. The water surface elevation can be easily calculated since the distance between the radar and the water surface is proportional to the travelling time of each pulse. This allows to derive wave parameters such as the significant wave height (for further information see [Mai and Zimmermann 2000]).

In order to optimise the results, a very important first step is to detect outliers and replace them by interpolated values. This is particularly important because the commercial radar sensors used were originally designed for level measuring in processing industries.

Then, the significant wave height calculated adopting the "WAFO" Matlab-libary, developed by the University Lund/Sweden. An example of long-term recording of the significant wave height is illustrated in Figure 2 (c).
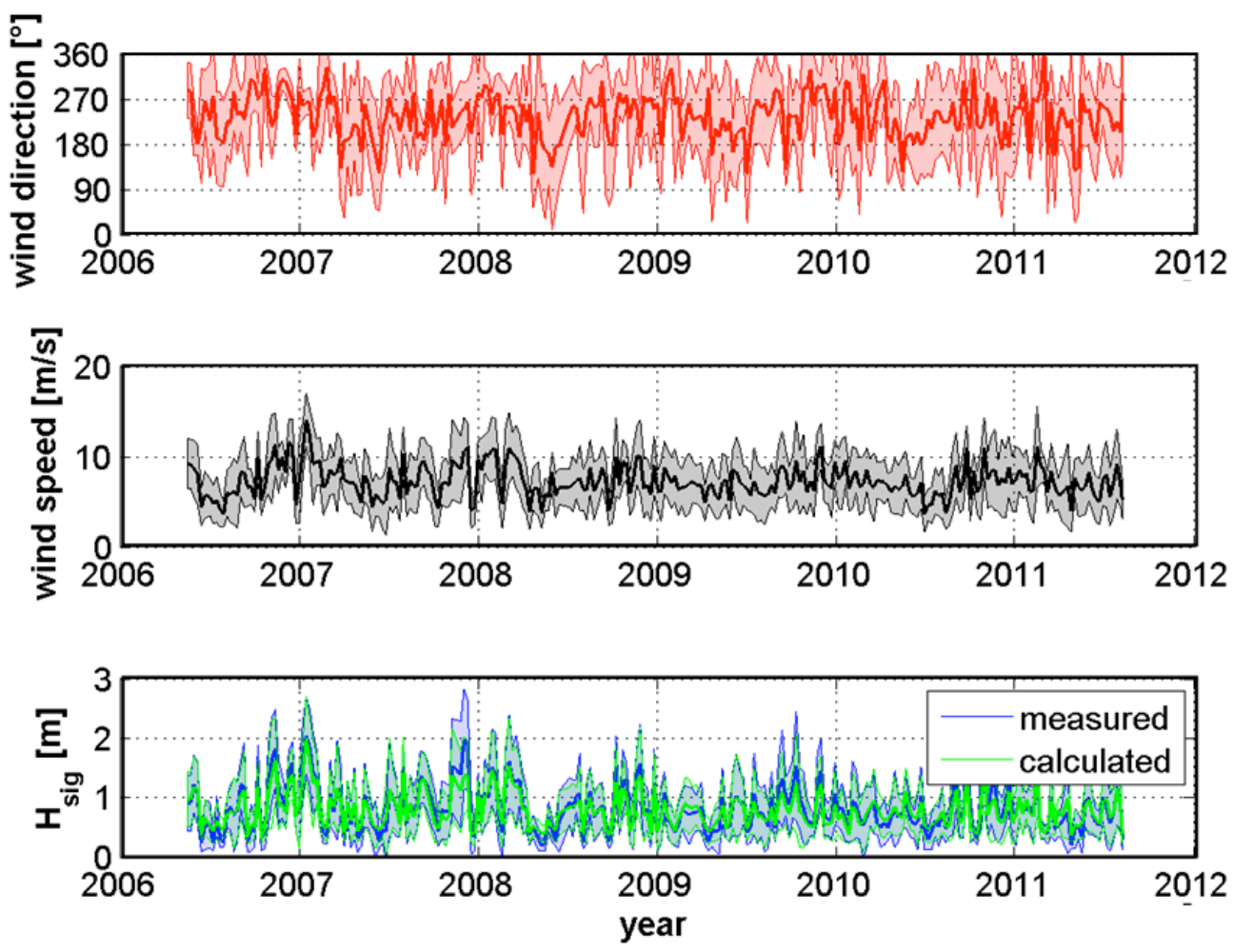

Figure 2: Illustration of the mean (bin size 1 week) wind direction (a) wind speed (b) and significant wave height (c) during the considered period. The shaded patches indicate the standard deviation. 
The precision of this system was tested under laboratory conditions as well as in the field [Wilhelm and Barjenbruch 2008]. The results of the wave-flume experiments reveal an accuracy better than $0.5 \mathrm{~cm}$ for $95 \%(\sigma=0.017 \mathrm{~cm})$ of the recorded significant wave heights. Amongst others, field tests were run on the offshore platform "Fino1" in the North Sea. There, the radar gauge is mounted close to the pillars of the platform. For reference, a waverider buoy is anchored at a distance of 100 meters. The comparison of the calculated significant wave heights shows only slight deviations without an significant trend. Thus, interactions of the sea with the structure that might affect the wave-height measurements seem to be unlikely. Further investigations of possible interactions will be made in another field experiment starting in July, 2012.

\section{WIND MEASUREMENTS}

Moreover, monitoring at the "Lighthouse Alte Weser" also includes wind parameters. A meteorological station of the Deutscher Wetter Dienst ( $D W D$ - German national meteorological service) records wind speed (Figure $2 \mathrm{~b}$ ) and direction (Figure $2 \mathrm{a}$ ) every minute at a height of 30 meters above the water surface. For preprocessing, the data are converted to local Cartesian coordinates ( $U$ =zonal wind component, $\mathrm{V}=$ meridional wind component) with respect to a reference level of 10 meters above the mean sea level (following Kleemann und Meliss [1993]).

\section{Climate data}

To predict future changes in significant wave heights, additional wind-data of the Global Climate Model "Echam5" is used. This comprehensive general circulation model of the atmosphere was developed by the Max Planck Institute for Meteorology. The data are given on a rotated pole grid with hourly resolution. As the "Lighthouse Alte Weser" is not located directly on a grid point of the model, the data need to be interpolated linearly to the exact position at first. Analyses of the interpolation methods indicate only slight differences (average deviation of $0,1 \mathrm{~m} / \mathrm{s}$ for $\mathrm{U}$ and $\mathrm{V}$ ) when choosing the nearest-neighbour method instead of linear interpolation.

The average variation of the wind speed is calculated with regard to its directionality to include directional changes. This is of particular importance, as the wave height at the "Leuchtturm Alte Weser" strongly depends on wind direction.

\section{RESULTS}

First, a transfer function of wind speed to wave height is presented. Based thereupon, an analysis of possible changes of wave heights due to possible future changes in wind statistics is given.

\section{Transfer function}

Obviously, various factors influence the wave generation at the "Lighthouse Alte Weser": wind speed, fetch, wind duration and water depth are commonly assumed to be the dominant parameters. At this particular observation site, some additional aspects may also play an important role. As it is located within the estuary of the River Weser, wind-current interaction could be relevant. Moreover, the water depth at the site (about 11 meter) is strongly tide-dependent. Due to the complexity of the processes involved, a deterministic calculation of the significant wave heights is almost impossible. 


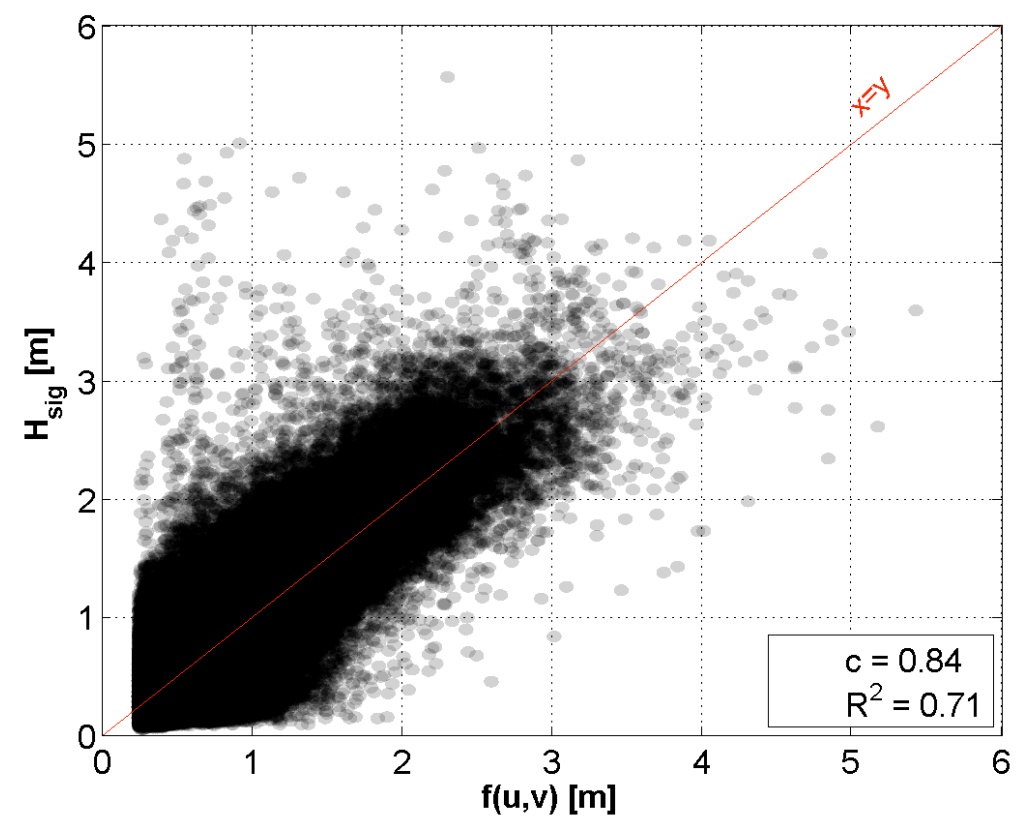

Figure 3: Scatter plot of the comparison of significant wave heights.

Assuming that all time-dependent differences will average out, due to the long time period of the recorded parameters, this study presents a simple transfer function for the location at "Lighthouse Alte Weser".

$$
H_{\text {sig }}[\mathrm{cm}]=f(U, V)=34,1+4,51 U-1,18 \mathrm{~V}+0,62 U^{2}+0,63 V^{2}
$$

It depends only on the zonal $(\mathrm{U})$ and meridional $(\mathrm{V})$ wind components. One possible interpretation of this function is that the wind stress, which is proportional to the square of the wind speed, is the fundamental impulse, whereas the linear correction terms include directional dependencies. The constant offset is partly determined by a lower measuring threshold of the radar gauge.

A comparison of the calculated and measured significant wave heights is shown in Figure 4, resulting in a correlation coefficient $\mathrm{c}=0.84$ with a $\mathrm{R}^{2}$ goodness of fit of 0.71 . Besides the expected scatter, there are only few larger deviations.

A comparison of the times series (Figure $2 \mathrm{c}$ ) shows an overall good agreement as well.

For a wind speed of $16 \mathrm{~m} / \mathrm{s}$ at $240^{\circ}$ a significant wave height of $\mathrm{H}_{\text {sig }}=2,06$ meter is estimated by the transfer function (1). This is in good agreement with the results given by Mai [2008], who derived a significant wave height of $\mathrm{H}_{\text {sig }}=1.80-2.20$ meters by applying the phase-averaged wave model SWAN.

Assuming that the transfer function will continue to hold under the possible future climate as projected by the model, the variability of the exceedance probability of the significant wave height and the wind speed can be analysed.

\section{Prediction of wave-height changes}

A general increase of the wind speed along with an increase of the significant wave height within the next years is suggested by the model (see Figure 5). An average increase of the $99 \%$ quantile of the significant wave height of $0.33 \mathrm{~cm} /$ year is indicated until 2060. In the next 30 years, the model predicts an average increase that is slightly lower $(0.17 \mathrm{~cm} /$ year $)$. One has to keep in mind that the uncertainty of predicted wind speed distribution can lead to large discrepancies in the results (up to 88\%). Mai and Zimmermann [2004] examined a climate scenario for the year 2050 near Solthörn. They determined an increase of the $99 \%$ quantile of the significant wave height of $0.4 \mathrm{~cm} /$ year, which 
is close to the results estimated in this study. However, they pointed out that a rise of the water level might be the dominating factor influencing the wave height in shallow regions, a circumstance which is not considered in this study.

The trend of $1.2 \mathrm{~cm} /$ year increase for the years 1958-2001 as determined by wind wave hindcasts [Weisse et al. 2003] seems to reduce slightly.
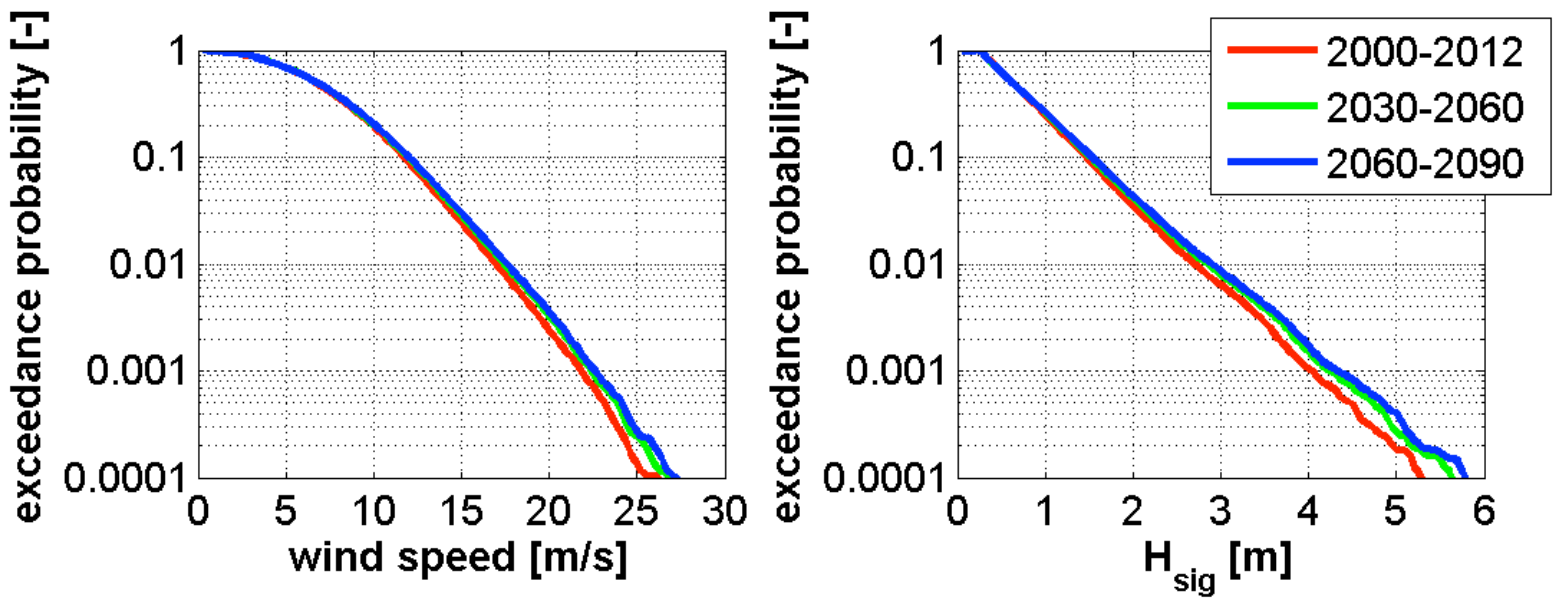

Figure 4: Exceedance probability of wind speed and significant wave height at the "Lighthouse Alte Weser"of several periods.

\section{CONCLUSION}

Although far away from being perfect, the presented transfer function yields results that are in good agreements with other methods. The derived change of the significant wave height at the "Lighthouse Alte Weser" suggests an average increase of the $99 \%$ quantile of $0.26 \mathrm{~cm} /$ year until the year 2090 . To detect long-term trends more accurately, continuous monitoring of sea-state parameters is indispensable. As demonstrated in this study, radar gauges have proven their suitability for long-term measurements.

\section{OUTLOOK}

So far, the wave-gauging station at "Alte Weser" is capable of monitoring wave heights and wave periods, while especially information about directionality is missing. Precisely these recordings would improve, on the one hand, numerical modelling of sea states [Haver and Nyhus 1986] and, on the other hand, the design of coastal and offshore structures. Bowers et al. [2000] underline that the maximum hawser tension at some structures may occur when the wind and waves are at $60-90^{\circ}$. They point out that the simple assumption of an aligned wind and wave direction is often invalid. They monitored a difference of $60^{\circ}$ before the storm is fully developed. Even at the peak of a storm, differences of $10-30^{\circ}$ are common.

To enlarge the capability towards monitoring of wave direction, the German Federal Institute of Hydrology - BfG (in cooperation with the German Federal Maritime and Hydrographic Agency - BSH) is developing an extension of the existing system based on an array of four radar sensors. Moreover, the upgraded system aims to offer the capability of analysing possible disturbances of wave measurements by the offshore structure itself.

A first test construction will be mounted at "Borkum Südstrand" in July, 2012. 
Acknowledgement

The results of this study are partly from the "KLIWAS" research program and partly from the BfG project "RiseARaF". Both funded by the Federal Ministry of Transport, Building and Urban

Development (BMVBS ). The authors thank Anette Ganske for support. The authors would also like to thank the water and shipping agency (WSA) Bremerhaven for the installation and maintenance of the radar gauge.

\section{CONTACT DETAILS}

Sebastian Rütten

Federal Institute of Hydrology

Department of Hydrometry and Hydrological Survey

Am Mainzer Tor 1

56068 Koblenz

Germany

Tel.: +4926113065336

Email: ruetten@bafg.de

\section{LITERATURE}

Bowers, J.A., Morton, I.D. and Mould, G.I. 2000. "Directional statistics of the wind and waves". Applied Ocean Research 22. 13-22

Haver,S. and Nyhus, K.A. 1986. "A Wave climate Cescription for long term response calculations". Proceedings of the fifth international offshore mechanics and arctic engeneering symposium, Vol 4, 27-34

Kleemann, M. and Meliss, M. 1993. Regenerative Energiequellen. Springer Verlag.

Mai, S. and Zimmermann, C. 2000. "Applicability of Radar Level Gauges in Wave Monitoring". Proc. Of the 2nd Int. Conf. Port Development \& Coastal Environment. Varne, Bulgaria

Mai, S. and Zimmermann, C. 2004. "Veränderung der Seegangsbedingungen an den Küsten von Jade und Weser als Folge der Klimaänderung". Coastline Reports 1.93-100

Mai, S. 2008. "Statistics of Waves in the Estuaries of the Rivers Ems and Weser-Measurement vs. Numerical Wave Model". COPEDEC VII, Dubai

Wang, X. L., Zwiers, F. W. and Swail, V. R. 2003. "North Atlantic Ocean Wave Climate Change Scenarios for the Twenty-First Century". Journal of climate, Vol 17

Weisse, R., Feser, F. and Günther, H. 2003, "Wind- Und Seegangsklimatologie 1958-2001 für die südliche Nordsee basierend auf Modellrechnungen", GKSS Report.

Wilhelmi, J. and U. Barjenbruch. 2008. "Application of Radar Gauges to measure the water level and the state of the sea". Proceedings of 31st International Conference on Coastal Engineering, Hamburg, Germany 